\title{
Stratigraphic and morphologic signatures of continental shelves, IGC 2016, Cape Town: an introduction
}

\author{
A. N. Green ${ }^{1}$ (D) J. A. G. Cooper ${ }^{1,2}$ \\ Received: 16 November 2017 / Accepted: 20 November 2017 \\ (C) Crown 2017
}

\begin{abstract}
This special issue of Geo-Marine Letters comprises seven contributions to the session "Stratigraphic and morphologic signatures of continental shelves" of the 35th International Geological Congress held in Cape Town (Republic of South Africa) on 27 August-4 September 2016. There is an additional article not presented at the conference but falling into the same general theme. The guest editors are A.N. Green and J.A.G. Cooper. The eight articles address several contemporary themes in continental shelf geology. They include the role of antecedent conditioning on the development of shelf stratigraphy and geomorphology; erosion of submerged shorelines and their preservation during (stepped) postglacial sea-level rise; the role of glacial processes (e.g. iceberg scouring during ice-sheet retreat); and the utility of archival data in addressing contemporary issues such as Holocene climate change and global oceanographic circulation systems. The continental shelf holds important information for understanding past and present global circulation and earth-ice-atmosphere interactions including sea-level change. It is hoped that these themes will spur further research that is slowly coming to the fore in several new and innovative mapping and exploration programmes emerging from an increasing number of coastal nations.
\end{abstract}

\section{Preamble}

The world's continental shelves hold a diverse range of information relevant to coastal response to sea-level change. Evidence from submerged shorelines and other elements of transgressive stratigraphy are extending the range of environmental settings and sea-level change scenarios beyond what is observable on contemporary shorelines, and providing new understanding of coastal response to forcing agents such as sediment supply and sea-level change.

Similarly, the preservation potential and reworking of coast and nearshore deposits on the shelf is receiving ever more attention. The way in which shelf sediments are preserved during either regression or transgression fundamentally affects their morphology and this in turn is critical for interpreting the shelf record of coastal

\section{A. N. Green}

greena1@ukzn.ac.za

1 Geological Sciences, University of KwaZulu-Natal, Durban, South Africa

2 School of Environmental Sciences, University of Ulster, Coleraine, UK evolution, changing climate and earth-ice-atmosphere interaction. Advances in technology and availability of data are fuelling this new phase of investigation of continental shelves. Multibeam bathymetry, increased resolution of seismic profiling, innovative sampling techniques and the increasing volume of data are all providing new insights into coastal and shelf processes. Added to this is higher-resolution dating that is enhancing understanding of past sea levels and the response of coasts and shelves to sea-level changes.

In the context of such progress, a dedicated session was convened at the 35th International Geological Congress held in Cape Town (RSA) on 27 August-4 September 2016. The session "Stratigraphic and morphologic signatures of continental shelves" drew over 120 delegates. This special issue, guest edited by A.N. Green and J.A.G. Cooper, includes papers based on several of those presentations. They illustrate the advances being made in contemporary continental shelf stratigraphy and sedimentology, and originate from a diverse spectrum of groups working on shelves around the world.

For the first time in many years, current research on the southern African shelf was showcased before the international community. This highlighted the growing importance of 
submarine geology in South African science and the rise of a young generation of marine geoscientists in the area.

\section{The contributions}

The papers in this special issue exemplify contemporary lines of enquiry into the geology and geomorphology of continental shelves. The study regions lie offshore South Africa, Mozambique, Spain, Russia and Brazil.

Green et al. and Pretorius et al. examine submerged shorelines from the shelf offshore SE Africa. They highlight the delicate interplay between transgressive erosion by wave ravinement and the preconditioning factors that promote shoreline preservation. The former paper, in particular, examines the role of antecedent shelf setting in establishing and later preserving palaeo-shorelines, sometimes in great detail. A number of positive feedback mechanisms between slope, propensity for rapid diagenesis and pre-existing backbarrier accommodation are discussed. Pretorius et al. further elaborate on the physical breakdown process of shorelines during the process of ravinement, and show this to be an episodic process driven by storm events impacting the upper shoreface even after transgression.

Geological control and inheritance of antecedent topography is further discussed from the Gulf of Cadiz by Lobo et al. and de Castro and Lobo. Lobo et al. document how major regressive erosional surfaces, in addition to the subsequent transgressive surfaces, are subject to complex interplays between the pre-existing geological controls and erosional style. They show how subtle changes in induration at the shelf scale can control the manner in which unconformities are formed and their spatial distribution influenced. The implications for the role of incised valley positioning, and subsequent preservation from wave ravinement are highlighted. de Castro and Lobo examine how inheritance of antecedent topography during deglaciation may feed back and modify the local hydrodynamics, further influencing the development and preservation of particular transgressive stratigraphic facets. These highlight the importance of site-specific controls on sequence stratigraphic models.

The significance of transgressive stratigraphies to the overall shelf sediment stack is emphasized by Vieira et al. They show the development of composite clinoform wedges on the south-eastern Brazilian shelf, which they relate to mixed transgressive/highstand systems tract deposition. Their formation is ascribed to a series of dislocated sediment sources, closely influenced by the evolving oceanographic regime during shelf transgression. This study affirms the fact that transgressive stratigraphic windows are no longer limited to the sedimentary fills of shelf-hosted incised valleys that escaped transgressive ravinement, but that other large shelf repositories can, and do, exist for this sea-level state. This too has implications for the traditional sequence stratigraphic models, especially along-strike predictions with areas of multiple, non-deltaic sediment sources.

Dorokhov et al. underline how new and detailed mapping of shelfscapes can reveal previously hidden seafloor features that aid in refining our understanding of patterns of ice retreat during deglaciation. They examine the south-eastern Baltic Sea from a multi-tool perspective, and discuss the development and preservation of extraordinary keel marks from ice-sheet retreat, iceberg calving and lake level lowering.

In contrast, the importance of archival datasets is emphasized by the papers of Flemming and Kudrass, and Flemming and Martin. (The former was not presented at the 35th IGC but has been included in this special issue because it falls into the same broad theme.) Flemming and Kudrass reveal new geological context for the debate surrounding the existence and behaviour of the Mozambique current offshore SE Africa. An integration of geological and geophysical observations of bedform distribution and morphology shows the existence of at least a quasipersistent Mozambique current, in contradiction with the oceanographic modelling of others. This stresses the importance of integrated geological and oceanographic observations in understanding complex circulation patterns. Flemming and Martin revisit historic seismic reflection profiles to examine trapping of Holocene-age fluvial sediment on the high-energy SE African margin. Supporting evidence is produced for contemporary sediment yields being closely matched with those averaged for the Holocene, showing a close similarity between the contemporary and mean Holocene hydro-climate of southern Africa. Again, an emphasis is placed on the importance of the antecedent conditioning that incipient geology and geomorphology exert on the accumulation of sediment-in this case, a thick highstand wedge.

Overall, it is clear that shelves are key areas that enable refinement of the sequence stratigraphic models that are currently in widespread use. In particular, their utility in unravelling late Pleistocene/Holocene-scale sea-level changes from non-coral-reef locations is extremely exciting. Stepped sea level, and especially the importance of stillstands during deglaciations, is an overlooked but important control on the styles of erosion and deposition on continental shelves. The articles in this special issue all highlight how detailed mapping, from both seismic and bathymetric perspectives, is an invaluable tool in the un- 
derstanding of contemporary, through ancient, shelf processes and stratigraphic development. By virtue of their shallowness, and often high-energy nature, these areas remain comparatively poorly understood in relation to slope and abyssal regions. It is hoped that this special issue will encourage further research on continental shelves, and promote the showcasing of the mapping and exploration programmes that are now currently underway in many coastal nations.
Acknowledgements We acknowledge the dedicated reviewers who, together with the editors Burg Flemming and Monique Delafontaine, provided critical insights and thoughtful perspectives on the papers. In particular, the editors are thanked for maintaining the momentum in collating everything required for this special issue.

\section{Compliance with ethical standards}

Conflict of interest The authors declare that there is no conflict of interest with third parties. 